\title{
Quantitative gas measurements using a versatile OPO-based cavity ringdown spectrometer and the comparison with spectroscopic databases
}

\author{
S. Persijn • F. Harren • A. van der Veen
}

Received: 7 October 2009 / Revised version: 16 November 2009 / Published online: 14 January 2010

(C) The Author(s) 2010. This article is published with open access at Springerlink.com

\begin{abstract}
A versatile OPO-based cavity ringdown spectrometer is reported for quantitative and sensitive gas measurement down to $\mathrm{nmol} / \mathrm{mol}$ levels. The system is based on cavity ringdown spectroscopy (CRDS) in combination with a continuous wave optical parametric oscillator tunable from 2693 to $3505 \mathrm{~nm}$. Using a single set of CRDS mirrors, spectra were recorded of methane, ethane, benzene, propane, water, acetone and formaldehyde. Gas mixtures were gravimetrically prepared in cylinders or via dynamic generation using diffusion tubes (formaldehyde). Results were compared with data from the Hitran, PNNL and NIST databases. Good agreement was found with PNNL and NIST data for most molecules while agreement with Hitran was less for ethane and formaldehyde.
\end{abstract}

\section{Introduction}

Gas monitoring systems based on laser spectroscopy have become standard equipment in industry and research environments due to their sensitivity, selectivity, and speed of measurement. Fields that are served include environmental monitoring, purity analysis of gases in the semiconductor industry, and leak detection in the oil and gas industry. Existing gas monitoring systems are in general limited to measurement of a single component as they are equipped with

S. Persijn $(\varangle) \cdot$ A. van der Veen

VSL, Thijsseweg 11, 2629 JA Delft, The Netherlands

e-mail: spersijn@vsl.nl

\section{F. Harren}

Life Science Trace Gas Facility, Institute for Molecules and Materials, Radboud University, 6525 ED Nijmegen, The Netherlands standard continuous wave diode lasers that lack wide tunability. Analysis of multiple components requires the use of a light source covering a wide wavelength range. In the near-infrared a multitude of inexpensive fibered lasers with a limited tuning range have been combined [1]. In the midinfrared range, recent developments with external cavity quantum cascade lasers are promising. Nowadays, tuning ranges exceeding $100 \mathrm{~cm}^{-1}$ in combination with an output power greater than $100 \mathrm{~mW}$ can be achieved [2]. Difference frequency generation sources based on widely available near-infrared lasers form another alternative. Employing waveguide instead of bulk PPLN crystals results in high conversion efficiencies with output powers up to tens of $\mathrm{mW}$ ([3] and references therein). Wide tuning can also be achieved by optical parametric oscillators (OPOs). Tuning ranges in the order of $1000 \mathrm{~cm}^{-1}$ in combination with output powers of more than 1 watt have been achieved [4-6]. Their high output power renders them ideal as a source for photoacoustic spectroscopic techniques $[7,8]$ while their narrow line width makes them also a useful source for highresolution spectroscopy $[9,10]$. Recently, several reviews have appeared that focus on developments in the design, operation, and spectroscopic applications of tunable OPOs $[11,12]$.

Accurate spectroscopic gas detection requires reliable spectroscopic data and good reference gas mixtures. When one only relies on spectroscopic data, knowledge of accurate absorption strengths and their uncertainty is of key importance. The Hitran and GEISA databases are two of the best known and most extensive resources containing several million line strengths of tens of molecules [13, 14]. Data are based on a combination of experimental work and theoretical calculations. They have proven to be useful resources for applications such as planetary observations or radiative transfer calculations. Care should be taken not to rely on 
these databases as a sole source for calibration of a gas detection system. If possible, calibration of the system with an appropriate set of certified reference gas mixtures should be performed. In some cases, this may not be possible such as in differential absorption LIDAR, combustion research or satellite measurements. However, one should be aware that this may lead to erroneous results. For example, using near-infrared spectroscopy, the SCIAMACHY instrument onboard ESA's ENVISAT satellite observed unexpectedly large tropical emissions of methane [15]. Recently however, a retrieval error was identified related to inaccuracies in water vapor spectroscopic parameters, causing an overestimation by $30 \%$ of methane amount correlated with high water vapor abundances [16]. Another example is formed by the formaldehyde line intensities in the strong $3.6 \mu \mathrm{m}$ band; Perrin and co-workers found out these to be on the average 28\% stronger than those quoted in the HITRAN 2004 database. Several studies are based on these incorrect line strengths [17]. Accurate determination of line strengths is complex and very time-consuming. The best results up to now reach an accuracy of $0.1 \%$ and have been obtained on well-isolated lines of small molecules such as $\mathrm{CO}_{2}$ [18].

Many molecules do not readily lend themselves to a lineby line description such as species possessing very dense spectra and numerous low-frequency modes of vibration. In this case, one has to rely on databases which encompass FTIR absorption spectra that are normally recorded at atmospheric pressure and temperature. Unfortunately, many of them suffer from low resolution, lack of sample quantification, and use of impure samples which limits the usefulness of these databases. Two databases which we do found useful are the NIST library and the PNNL database [19, 20]. Data consists of composite spectra obtained from measurements on at least 9 different partial pressures of the compound. For both databases an extensive description of the used methods and accuracy budget is available. For most compounds, the relative expanded uncertainty $(k=2)$ of the NIST database is between $2 \%$ and $2.3 \%$ and it is lower than $3.1 \%$ for the PNNL database. The instrumental resolution is 0.125 and $0.112 \mathrm{~cm}^{-1}$, respectively. It should be noted that both databases just like any FTIR library have limitations regarding applications outside their intended temperature and pressure ranges.

Here, we report on a spectrometer which can quantitatively detect tens of different gases down to $\mathrm{nmol} / \mathrm{mol} \mathrm{lev-}$ els. The system is based on cavity ringdown spectroscopy (CRDS) [21] in combination with a continuous wave optical parametric oscillator tunable from 2693 to $3505 \mathrm{~nm}$. Using a single set of CRDS mirrors, spectra over typically several wavenumbers were recorded of a variety of compounds including ethane, benzene, propane, acetone and formaldehyde. Gas mixtures were gravimetrically prepared in cylinders or via dynamic generation using diffusion tubes (formaldehyde). Results were compared with data from the Hitran, PNNL and NIST databases. Finally, the system was applied to the purity analysis of carbon monoxide and methane.

\section{Experimental approach}

A schematic of the experimental set-up is shown in Fig. 1 which encompasses a continuous wave optical parametric oscillator in combination with cavity ringdown spectroscopy. As a pump source for the optical parametric oscillator a 7.8 watt, single-frequency DFB fiber laser centered at $1063.9 \mathrm{~nm}$ is operated (Koheras). The laser can be tuned thermally over $45 \mathrm{GHz}$ or via applying a tensile strain to the fiber using a multi-layered piëzo over $53 \mathrm{GHz}$ (fast). The combined tuning range is $90 \mathrm{GHz}$. The stated line-width of the laser is better than $70 \mathrm{kHz}$. After passing through a free-space isolator (Electro-Optics Technology), the pump laser is tightly focused in a MgO-doped (5 mol\%) congruent periodically-poled lithium niobate (PPLN) crystal $(50 \mathrm{~mm} \times 8 \mathrm{~mm} \times 0.5 \mathrm{~mm})$ with poling periods ranging from 28.5 to $31.5 \mu \mathrm{m}$ (HC Photonics). The crystal has $1^{\circ}$ wedges on both sides to reduce etalon effects and suppress feedback into the pump laser. The crystal is placed in an oven made of peek (polyetheretherketones), which can be machined much easier compared to the more commonly used ceramic materials. The crystal is placed in a bow-tie optical cavity which is resonant for the signal wavelength. A $400 \mu \mathrm{m}$ thick solid uncoated YAG etalon (free spectral range is $7 \mathrm{~cm}^{-1}$ ) is placed in the cavity to suppress mode hops.

The OPO cavity is enclosed in a thick aluminum housing which is flushed with dry nitrogen to improve the stability

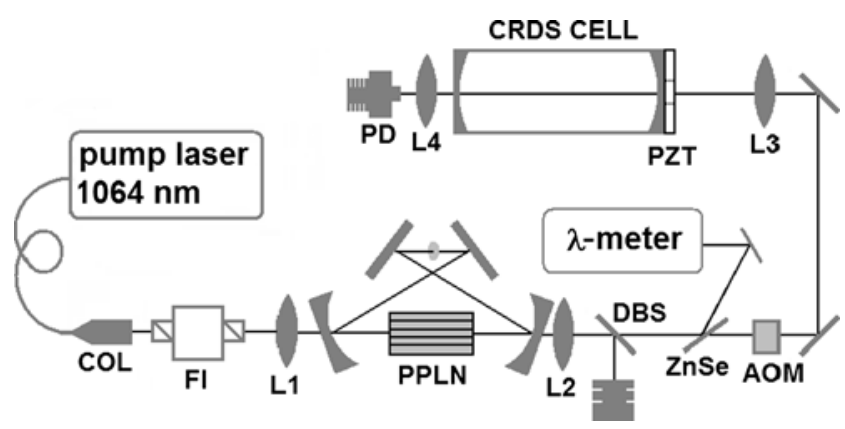

Fig. 1 Light from the pump laser is coupled into the OPO via a collimator (COL), Faraday isolator (FI) and AR-coated focusing lens (L1). The output of the OPO is collimated using an uncoated $\mathrm{CaF}_{2}$ lens (L2). Signal and residual pump are separated from the idler using a dichroic beams splitter (DBS). Part of the idler beam is directed to a wavelength meter using a $\mathrm{ZnSe}$ window placed near Brewster angle. The idler is guided through an acousto-optic modulator (AOM), and via mode-matching optics (L3) coupled into the ringdown cavity. Length of the cell is modulated at $35 \mathrm{~Hz}$ using a ring piëzo (PZT). Light emerging from the cell is focused with a lens (L4) on a fast photodetector (PD) 
and output power at certain wavelengths that are absorbed by gases in the atmosphere. The idler wavelength can be tuned from 2693 to $3505 \mathrm{~nm}$ with a maximum idler output power of 1.2 watt around $3270 \mathrm{~nm}$. The idler wavelength is measured using a wavelength meter (model 621A, Bristol instruments). The stability of the idler frequency (better than $30 \mathrm{MHz}$ over a period of 10 seconds) and power are good taking into consideration that no active stabilization is used.

A standard detection scheme is used to record the ringdown events. The $40 \mathrm{~cm}$ long cavity consists of two highly reflective mirrors from Los Gatos Research Inc. with a maximum reflectivity of $99.987 \%$ at $3150 \mathrm{~cm}^{-1}$ (corresponding to a decay time of $10.5 \mu \mathrm{s})$. The cell volume is $150 \mathrm{ml}$. The cavity length is modulated over one free spectral range at a frequency of $35 \mathrm{~Hz}$ by means of a ring piezo-electric transducer attached to one of the mirrors. Light emerging from the cell is focused on a Peltier-cooled $(\mathrm{HgCdZn}) \mathrm{Te}$ photodetector (PVI-2TE-5, Vigo Systems S.A.). Once sufficient intracavity light intensity has built up, the idler beam is rapidly extinguished using an acousto-optic modulator as a fast switch. Spectra are recorded by measuring the ringdown time as function of the frequency. For spectra spanning up to $53 \mathrm{GHz}$, only pump laser tuning is used which takes about 90 seconds per scan. For spectra up to $210 \mathrm{GHz}$, this is combined with scanning of the etalon, while for even wider spectra temperature tuning of the PPLN crystal is needed [22]. Typically ten scans are averaged. The minimum detection limit is $6 \times 10^{-8} \mathrm{~cm}^{-1}$ in the short-term (1 second) and $5 \times 10^{-9} \mathrm{~cm}^{-1}$ in the long-term (5 minutes) at $3150 \mathrm{~cm}^{-1}$.

The gas flow from the cylinders to the cell is regulated using mass flow controllers (flow rate between 5 and $30 \mathrm{l} / \mathrm{h}$ ). At the exit of the cell, a combination of a pressure regulator and a membrane pump are used to maintain a constant pressure in the cell during operation. The ringdown cell is equipped with a pressure sensor (Edwards Barocel) and thermistor (Tempcontrol) for temperature measurements. Measurements in this work were recorded at atmospheric pressure and a temperature of $(20 \pm 1)^{\circ} \mathrm{C}$.

All gas mixtures used in this work were prepared in house. Formaldehyde was generated dynamically following ISO 6145. All other compounds were prepared as cylinder mixtures following ISO 6142 which describes the preparation of calibration gas mixtures using gravimetric method. Keys to the accurate preparation are the use of high purity compounds, suitable cylinders and good facilities for weighing gas cylinders. Relative measurements are done against a reference cylinder to compensate external variables such as the changes of the temperature, humidity and buoyancy. The nitrogen which was used for preparing the gas mixtures was of high purity and was analyzed separately on impurities. Amount of substances ranged from $10 \mathrm{nmol} / \mathrm{mol}$ up to $5 \mu \mathrm{mol} / \mathrm{mol}$ with typical uncertainties of less than 1 percent. Mixtures were made in 5 liters cylinders with a pressure of about 100 bars.
The accuracy of the derived measurements depends on several factors including uncertainties in pressure and temperature, interferences by other compounds, and photodetector non-linearity. In comparison to near-infrared photodetectors, mid-infrared photodetectors have a markedly larger non-linearity [23]. The non-linearity results in an overestimation of the decay times both of the sample and background (high purity nitrogen). Overall the calculated absorption coefficients will be too small. The non-linearity of the photodetector used in this work was measured to be $\leq 0.5 \%$ over the intensity range used. The influence of the time response of the photodetector ( $20 \mathrm{~ns}$ ) is negligible as typical decay times are between $5 \mu$ s and $10 \mu \mathrm{s}$. For strong absorptions, the expanded uncertainty $(k=2)$ of the measured absorption coefficients is about between $2 \%$ and $3 \%$. In case of strong interferences (often water vapor) or at the edge of the ringdown mirror reflectivity bandwidth, this value is higher. Note that we assumed that the concentration of the compound in the ringdown cell equals that of the gravimetrically determined value. This might not be correct for all compounds due decomposition or polymerization of the compound (e.g. formaldehyde) or adsorption in the flow system or gas cylinder (especially an issue for polar molecules like acetone).

\section{Experimental results ethane $\left(\mathrm{C}_{2} \mathrm{H}_{6}\right)$}

Figure 2 depicts a measurement of $10 \mathrm{nmol} / \mathrm{mol}$ ethane and of pure nitrogen. A good signal to noise is obtained at this low concentration level. The detection limit for ethane is below $1 \mathrm{nmol} / \mathrm{mol}(\mathrm{SNR}=3)$. In nitrogen the increasing decay time at higher frequencies is due to a small yet significant increase in mirror reflectivity over this short wavelength range.

Figure 3a shows a recorded spectrum of $50 \mathrm{nmol} / \mathrm{mol}$ ethane together with spectra from Hitran and PNNL data-

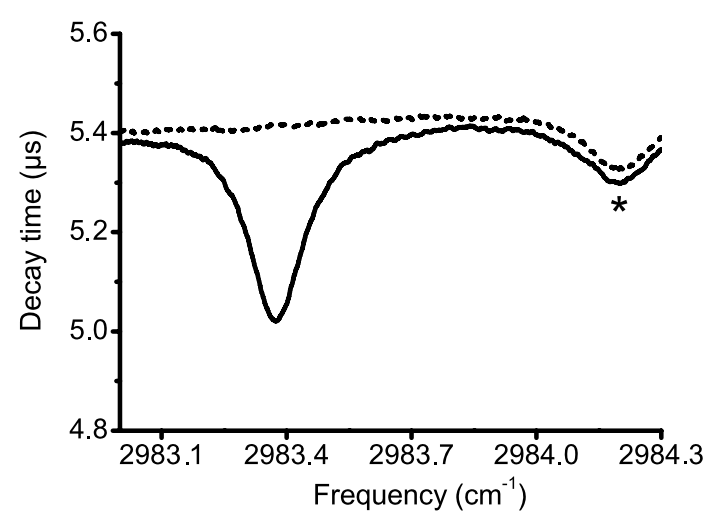

Fig. 2 Observed decay time for a mixture of $10 \mathrm{nmol} / \mathrm{mol}$ ethane (solid line) in nitrogen and of pure nitrogen (dashed line). An asterisk marks a water absorption line 


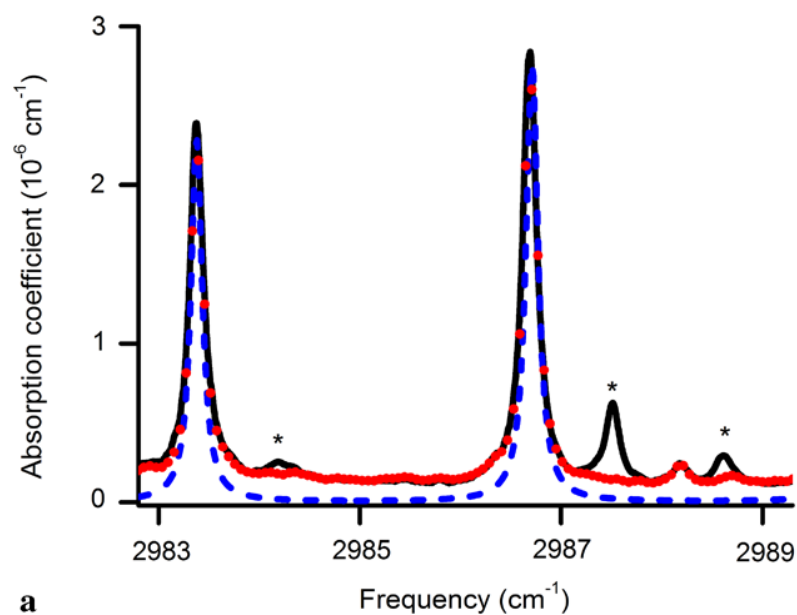

$\mathbf{a}$

Fig. 3 a Measurement of $50 \mathrm{nmol} / \mathrm{mol}$ ethane (solid black line) and the comparison with PNNL (red dots) and Hitran (dashed blue line). Peaks in the measurements marked by an asterisk are due to water vapor. b Linearity of the peak signal measured at $2990 \mathrm{~cm}^{-1}$ for amount

bases. Our measurements agree within their combined uncertainty with PNNL. While the peak heights in Hitran match those of our measurements and of PNNL many of the weaker lines (giving rise to the absorption in between the strong peaks) are missing in Hitran. In addition, the position of the peak at $2986.7 \mathrm{~cm}^{-1}$ in Hitran is shifted in agreement with observations by NASA [24]. The incompleteness of Hitran is due to the complexity of the ethane spectrum at $3 \mu \mathrm{m}$. Many interacting vibrational modes and the presence of hot bands make it difficult to accurately predict the spectrum. This is also recognized in the most recent Hitran paper which states about the $\nu_{7}$ band at $3.3 \mu \mathrm{m}$ [13]: '.. this band is sorely in need of improvement...'. Figure $3 b$ shows the good linearity of measured absorption coefficients. Amount of substances below $25 \mathrm{nmol} / \mathrm{mol}$ were obtained by dynamic dilution using mass flow controllers.

\section{Experimental results dynamically generated formaldehyde $\left(\mathrm{CH}_{2} \mathrm{O}\right)$}

Formaldehyde $\left(\mathrm{CH}_{2} \mathrm{O}\right)$ mixtures were prepared from paraformaldehyde powder (Merck). The paraformaldehyde was kept in glass diffusion tubes in an oven heated to $60^{\circ} \mathrm{C}$. The formaldehyde amount of substance was determined by periodic weighing of the diffusion tube and measuring the flow rate (Fig. 4). High flow rates of typically several 1/min were required as formaldehyde is strongly polar and in order to get sufficiently low formaldehyde levels.

After subtraction of water vapor and methane interference the measurement results agreed excellently with PNNL (Fig. 5). Also agreement with Hitran 2008 is good except near $2950 \mathrm{~cm}^{-1}$ where Hitran line strengths are too high. In

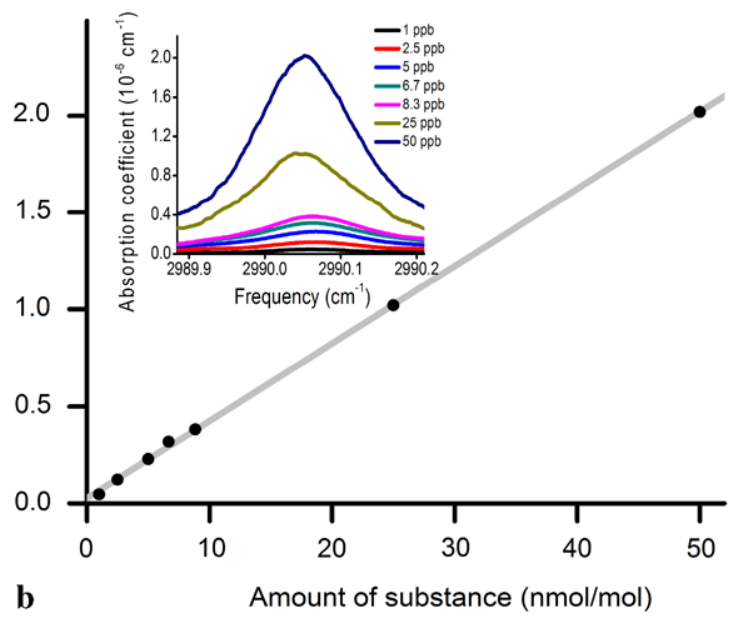

of substances ranging from 1 to $50 \mathrm{nmol} / \mathrm{mol}$ ethane. The corresponding slope is $(3.99 \pm 0,03) \times 10^{-8} \mathrm{~cm}^{-1} /(\mathrm{nmol} / \mathrm{mol})$. The inset shows the corresponding spectra

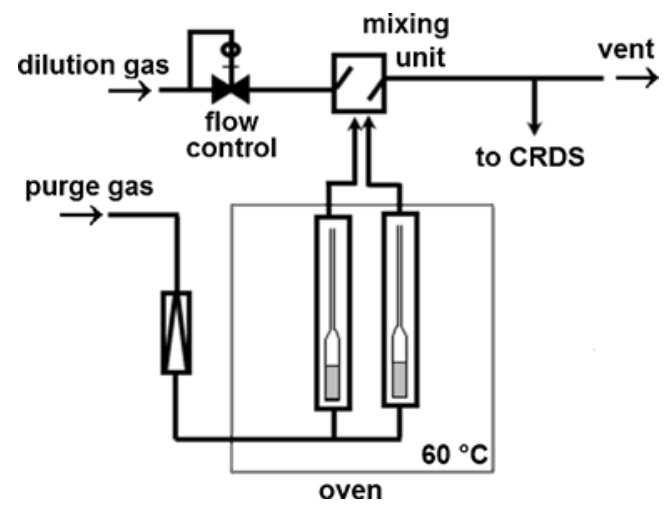

Fig. 4 Set-up for dynamic generation of formaldehyde by heating diffusion tubes containing paraformaldehyde to $60^{\circ} \mathrm{C}$

Hitran 2004 most peaks are 30\% too weak while the peak at $2950 \mathrm{~cm}^{-1}$ is much too strong. Many of the smaller peaks are completely absent in this version of Hitran. Formic acid, which might also be formed, was not detected.

To test the linearity of the system different amount of substances were made using a set of different diffusion tubes and dilution flows (Fig. 6). The spectral region lying between 2949.8 and $2951.3 \mathrm{~cm}^{-1}$ was selected for the CRDS measurements as absorption of water and methane are very weak in this wavelength region.

Using the absorption coefficients from PNNL 2.3\% higher amount of substances were found than the values obtained from the weighing. The expanded uncertainty in the dynamic preparation of formaldehyde in this experiment is large with $7 \%$. This has been attributed to use of diffusion tubes with a short neck which led to instabilities in the mass loss rate. In later experiment using diffusion tubes with a 
Fig. 5 a Measurement of $1.3 \mu \mathrm{mol} / \mathrm{mol}$ formaldehyde (blue line) and after subtraction of water and methane interference (black dashed line). Good correspondence is observed with PNNL (red dots). b Comparison of the cleaned measurement spectrum (black line) with Hitran 2004 (blue dashed line) and 2008 (red line)

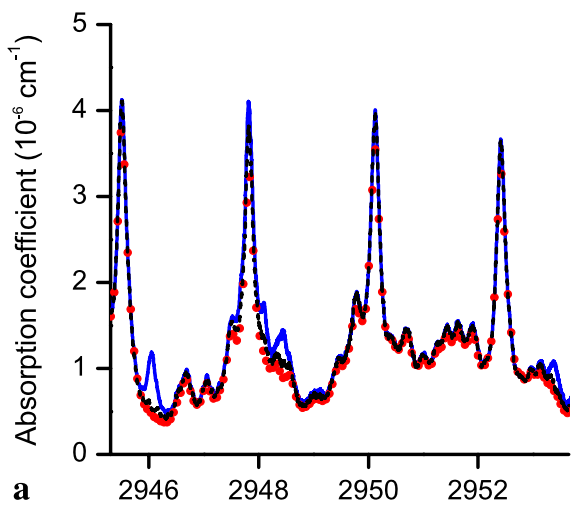

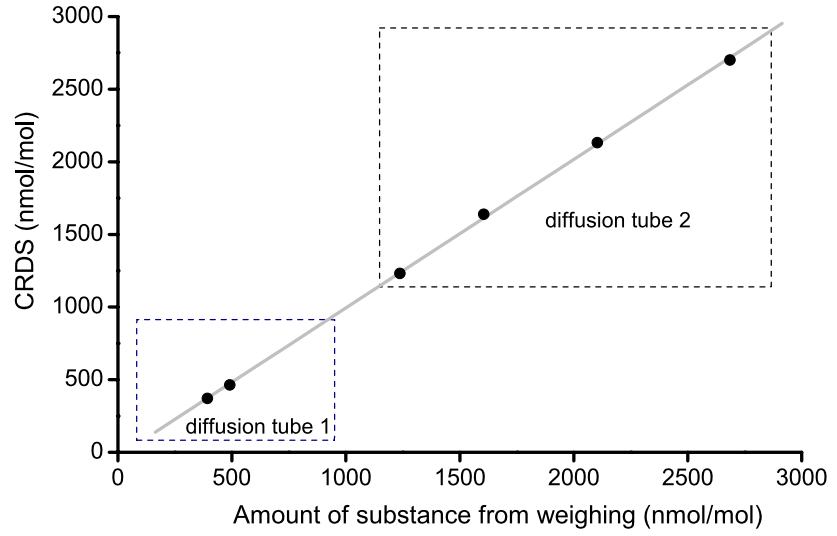

Fig. 6 Comparison of the measured (using the PNNL absorption coefficients) and set amount of substances. The slope of the linear fit is $1.023 \pm 0.008$

longer neck, the expanded uncertainty in the amount of substance could be reduced to $3.5 \%$.

\section{Experimental results benzene $\left(\mathrm{C}_{6} \mathrm{H}_{6}\right)$, acetone $\left(\mathrm{C}_{3} \mathrm{H}_{6} \mathrm{O}\right)$, and propane $\left(\mathrm{C}_{3} \mathrm{H}_{8}\right)$}

At atmospheric conditions, the spectra of acetone, propane and benzene in the $3 \mu \mathrm{m}$ region do not exist out of wellisolated lines but of a very broad absorption band spanning from 100 to $200 \mathrm{~cm}^{-1}$. Recording the entire spectra would be very time-consuming with the current set-up as it requires multiple changes in the crystal temperature. Therefore we chose to focus on the Q-branch regions which are much narrower but still specific for each molecule.

Figure 7 shows a measurement of $1 \mu \mathrm{mol} / \mathrm{mol}$ benzene around $3100 \mathrm{~cm}^{-1}$. This feature is relatively narrow and was therefore chosen instead of the $30 \%$ stronger but broader absorbing feature centered at $3047 \mathrm{~cm}^{-1}$. After subtraction of water vapor interference, good agreement is obtained with both NIST and PNNL databases.

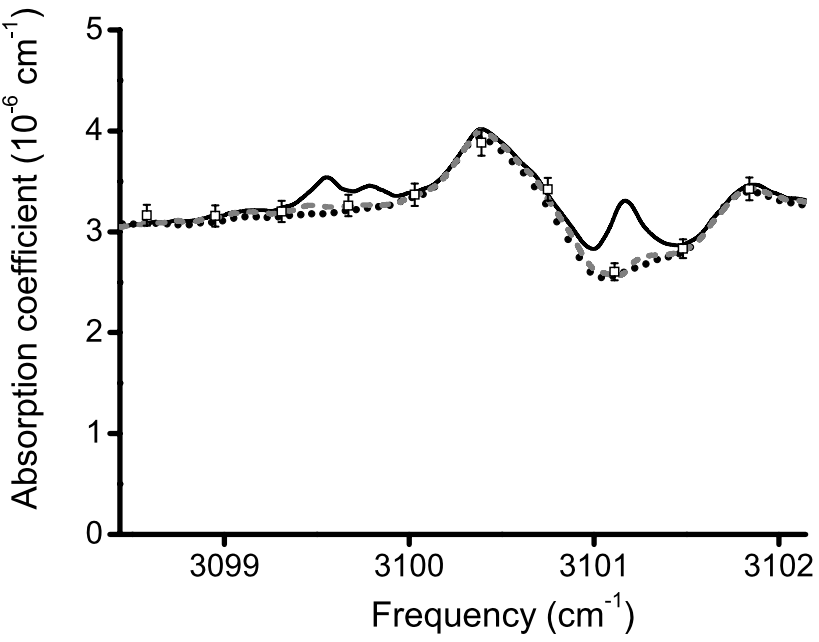

Fig. 7 Measurement of $1 \mu \mathrm{mol} / \mathrm{mol}$ benzene (black line) and after subtraction of water vapor interference (dashed grey line). Spectra from PNNL (black dots) and NIST (black squares including expanded uncertainty) database are also shown

For acetone a $5 \mu \mathrm{mol} / \mathrm{mol}$ mixture was available. The absorption by this sample is too high at the peak of the absorption and therefore the mixture was diluted with pure nitrogen using mass flow controllers to an amount of substance fraction of $1.67 \mu \mathrm{mol} / \mathrm{mol}$ (Fig. 8).

Qualitatively good agreement is obtained with both PNNL and NIST databases. However the values we measured are consistently 5\% higher, most clearly visible at the peak of the absorption. Measurements with new mixtures are planned to sort out the difference. From the inset in Fig. 8, it can be seen that the maximum absorption coefficient that can be measured is about $10^{-5} \mathrm{~cm}^{-1}$ at this mirror reflectivity; above this the recorded spectrum becomes unreliable.

For propane a $1 \mu \mathrm{mol} / \mathrm{mol}$ mixture was available. As propane absorbs very strongly at $3 \mu \mathrm{m}$, the mixture was further diluted using mass flow controllers to yield a concentration of $200 \mathrm{nmol} / \mathrm{mol}$. This resulted in an increased uncertainty in the amount of substance of $(2.00 \pm 0.03) \times$ 


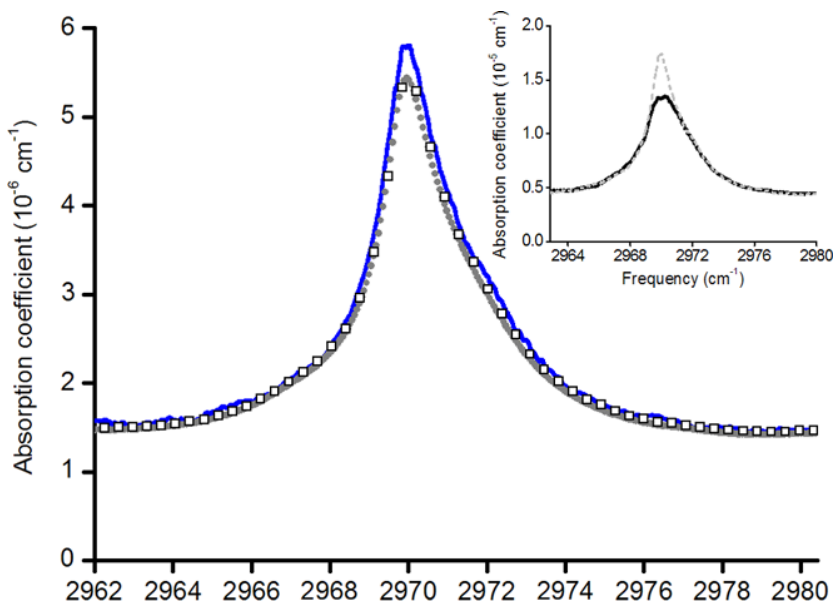

Fig. 8 Measurement of $1.67 \mu \mathrm{mol} / \mathrm{mol}$ acetone (solid blue line) and the comparison with PNNL (grey dots) and NIST (squares) database. The inset shows a measurement of $5 \mu \mathrm{mol} / \mathrm{mol}$ (black line) and a scaled measurement of $1.67 \mu \mathrm{mol} / \mathrm{mol}$ (grey dashed line, multiplied by $5 / 1.67)$

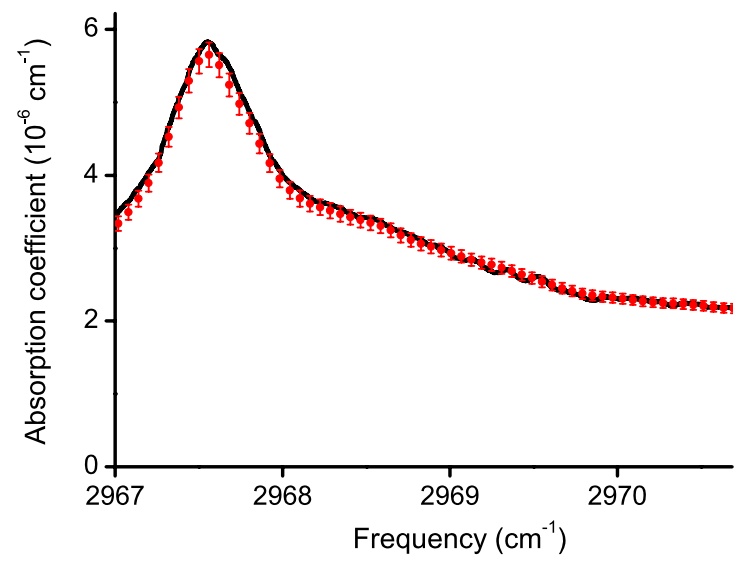

Fig. 9 Measurement of $200 \mathrm{nmol} / \mathrm{mol}$ propane (solid line) and the comparison with PNNL database (red dots including expanded uncertainty)

$10^{-7} \mathrm{~mol} / \mathrm{mol}$. Figure 9 shows the results. Absorption coefficients match within their combined uncertainty $(<3 \%$ for the PNNL data and $3.4 \%$ for our data).

\section{Application to purity analysis}

Pure reference materials play an essential role in the traceability chain for chemical measurements as one has to identify the entities concerned. The high sensitivity of our set-up renders it very suitable to quantify the often low levels of impurities present. Not only infrared-inactive molecules (e.g., nitrogen and oxygen) but also many infrared active molecules can be analyzed for their purity due to the wide tuning capability of the OPO.

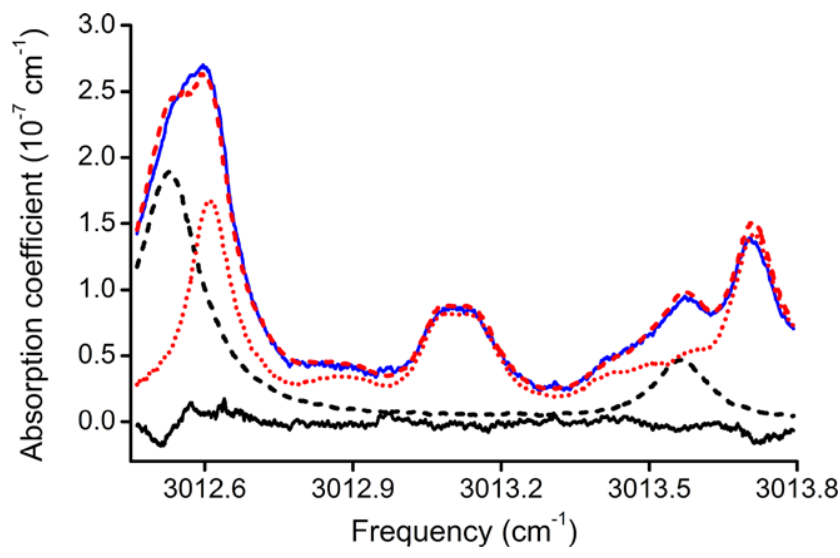

Fig. 10 Measurement of $\mathrm{CO}$ with purity 4.7 (solid blue line) and the corresponding fit (dashed red line) which is the sum of the absorption of $1.6 \mu \mathrm{mol} / \mathrm{mol} \mathrm{H}_{2} \mathrm{O}$ (dashed black line) and $12 \mathrm{nmol} / \mathrm{mol} \mathrm{CH}_{4}$ (dotted red line). The solid black line represents the residual of the measurement and the fit. Individual $\mathrm{H}_{2} \mathrm{O}$ and $\mathrm{CH}_{4}$ spectra were recorded in nitrogen. A small background absorption of $3 \times 10^{-8} \mathrm{~cm}^{-1}$ was subtracted from the measurement data (due to the presence of a large absorbing molecule or far wing absorptions by $\mathrm{CO}$ )

Figure 10 depicts a measurement of pure carbon monoxide (CO) which reveals several absorption peaks that can be attributed to $\mathrm{H}_{2} \mathrm{O}$ and $\mathrm{CH}_{4}$. The measured spectrum can be well fitted by the spectra of $\mathrm{H}_{2} \mathrm{O}$ and $\mathrm{CH}_{4}$ that were recorded before hand in nitrogen. This indicates that the pressure broadening coefficients must be similar in these two matrices.

Figure 11a shows the measurement of two pure methane samples containing different traces of water vapor. The measured spectrum consists of methane and water absorption on top of a broad background absorption of about $3.3 \times 10^{-6} \mathrm{~cm}^{-1}$. Such high background absorption was found in methane from different suppliers. It is due to far wing absorptions by methane itself. Also shown is the methane spectrum as calculated from Hitran 2008. No broad background is present, as in our calculation we did not take into account the contributions from distant methane lines which are up to 6 orders of magnitude higher. Band absorption data for methane have been developed as methane dominates part of the infrared spectra of the giant outer planets and Titan. From the data of Irwin and co-workers a three times higher background absorption of $1 \times 10^{-5} \mathrm{~cm}^{-1}$ can be derived at this wavelength range [25]. Nevertheless, a quite good correspondence between Hitran 2008 and our measurements is observed taking into account that the absorption is weak (maximum line strength $1.6 \times 10^{-26} \mathrm{~cm}^{-1} /\left(\right.$ molecule $\left.\left.\mathrm{cm}^{-2}\right)\right)$. The quality of the methane data in this wavelength range has been drastically improved in this version of Hitran as compared to Hitran 2004, which suffered from incorrect line positions and intensities.

Figure 11b shows the difference spectrum of the wet and dry methane samples. The shape of this spectrum is signif- 


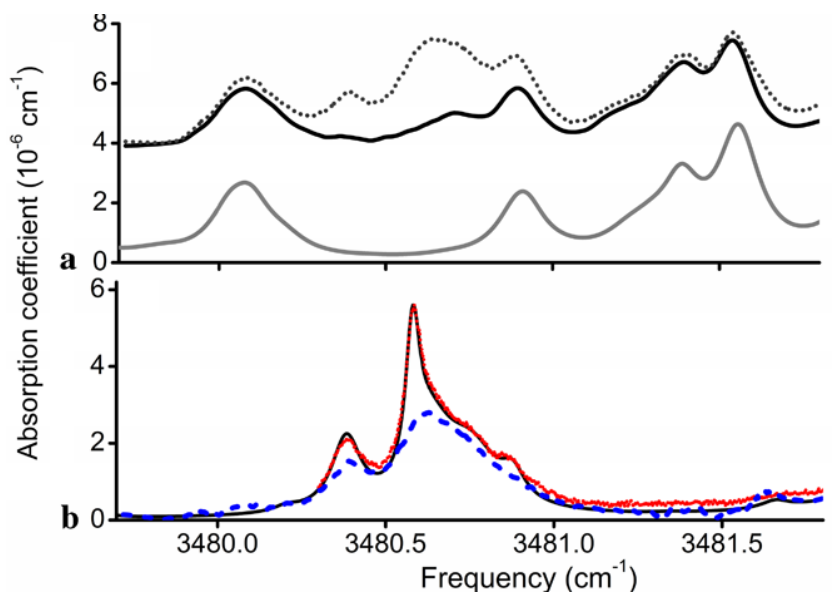

Fig. 11 a Recording of two methane samples containing a high (grey dots) and low (solid black line) amount of water vapor. Also the $\mathrm{CH}_{4}$ spectrum (grey solid line) calculated from Hitran is shown. b Difference spectrum of the high and low humidity $\mathrm{CH}_{4}$ samples (dashed blue line). For comparison the measured (solid black) and Hitran (light red dots) spectrum of $25 \mu \mathrm{mol} / \mathrm{mol} \mathrm{H}_{2} \mathrm{O}$ in $\mathrm{N}_{2}$ is shown

icantly different from the $\mathrm{H}_{2} \mathrm{O}$ spectrum as recorded in nitrogen, indicating different pressure broadening coefficients. The amount of substance of water vapor is obtained by integration of the area under the spectra yielding $21 \mu \mathrm{mol} / \mathrm{mol}$ for the wet sample and less than $2 \mu \mathrm{mol} / \mathrm{mol}$ for the dry sample.

\section{Discussion and conclusions}

A versatile OPO-based CRDS spectrometer was presented for quantitative gas measurements. The wide tuning range of the OPO enables detection of tens of different compounds. Compounds included several molecules with broad absorption patterns such as acetone and benzene which could be specifically measured by recording the Q-branch spectra. Good agreement was obtained with PNNL and NIST databases while agreement with Hitran for in particular ethane and to lesser extent also formaldehyde was less satisfactory. This work shows that results from CRDS are quantitative and are comparable with the FTIR data from PNNL and NIST (which were recorded at much higher concentration levels). With the current state of the art it is not advisable for most molecules to solely rely on Hitran as a source for quantitative gas measurements.

The presented system can be significantly improved in a number of ways. Currently, spectra spanning up to $7 \mathrm{~cm}^{-1}$ can be readily recorded using a combination of pump and etalon tuning. Access to wider spectral ranges requires timeconsuming temperature tuning of the PPLN crystal. To overcome this, one could replace the pump laser by an external cavity tunable low power seed laser in combination with a high power fiber amplifier. The latter are becoming rapidly cheaper and continuous tuning over hundreds of wavenumbers should be feasible [26]. An additional advantage is that (nearly) all measurements can be done in a single period of the crystal while currently tweaking of the idler beam may be required upon changing the crystal period. To increase the sensitivity of the system further we are currently testing new cavity ringdown mirrors with a higher reflectivity. In addition, we plan to lock the cavity to the OPO wavelength to increase the number of ringdown events that are sampled per second by a factor of 10 to 1000 [27]. The combined effect of these two measures should lead to 10-100 lower detection limits for most molecules. Finally, better modematching and temperature control of the cell are needed to push the expanded uncertainty in the measurements to less than $1 \%$.

Acknowledgements The authors thank the colleagues from the department of calibration and reference materials for preparing the gas mixtures, and Annarita Baldan for her contribution to the formaldehyde experiments. We also acknowledge Patrick Irwin (Clarendon Laboratory) for performing the band calculations for methane. This work was financially supported by the Dutch Ministry of Economic Affairs and the European Community's 7th Framework Programme, ERA-NET ${ }^{+}$, under the iMERA ${ }^{+}$project—grant agreement No. 217257.

Open Access This article is distributed under the terms of the Creative Commons Attribution Noncommercial License which permits any noncommercial use, distribution, and reproduction in any medium, provided the original author(s) and source are credited.

\section{References}

1. Y. Ding, P. Macko, D. Romanini, V. Perevalov, S.A. Tashkun, J.L. Teffo, S.M. Hu, A. Campargue, J. Mol. Spectrosc. 226, 146 (2004)

2. R. Maulini, I. Dunayevskiy, A. Lyakh, A. Tsekoun, C.K.N. Patel, L. Diehl, C. Pflügl, F. Capasso, Electron. Lett. 45, 107 (2009)

3. D. Richter, A. Fried, P. Weibring, Laser Photon. Rev. 3, 343 (2009)

4. A. Henderson, R. Stafford, Opt. Express 14, 767 (2006)

5. M. Vainio, J. Peltola, S. Persijn, F.J.M. Harren, L. Halonen, Opt. Express 16, 11141 (2008)

6. J. Kiessling, R. Sowade, I. Breunig, K. Buse, V. Dierolf, Opt. Express 17, 87 (2009)

7. F. Kühnemann, K. Scheider, A. Hecker, A.A.E. Martis, W. Urban, S. Schiller, J. Mlynek, Appl. Phys. B 66, 741 (1998)

8. A.K.Y. Ngai, S.T. Persijn, I.D. Lindsay, A.A. Kosterev, P. Gross, C.J. Lee, S.M. Cristescu, F.K. Tittel, K.J. Boller, F.J.M. Harren, Appl. Phys. B 89, 123 (2007)

9. H. Verbraak, A.K.Y. Ngai, S.T. Persijn, F.J.M. Harren, H. Linnartz, Chem. Phys. Lett. 442, 145 (2007)

10. E.V. Kovalchuk, D. Dekorsy, A.I. Lvovsky, C. Braxmaier, J. Mlynek, A. Peters, S. Schiller, Opt. Lett. 26, 1430 (2001)

11. B.J. Orr, Y. He, R.T. White, Spectroscopic applications of tunable optical parametric oscillators, in Tunable Laser Applications, 2nd edn. (CRC Press, New York, 2008)

12. A.K.Y. Ngai, S.T. Persijn, M.M.J.W. van Herpen, S.M. Cristescu, F.J.M. Harren, Photoacoustic spectroscopy using continuous wave optical parametric oscillators, in Mid-Infrared Coherent Sources and Applications (Springer, Dordrecht, 2008) 
13. L.S. Rothman, I.E. Gordon, A. Barbe, D. Chris Benner, P.F. Bernath, M. Birk, V. Boudon, L.R. Brown, A. Campargue, J.P. Champion, K. Chance, L.H. Coudert, V. Dana, V.M. Devi, S. Fally, J.M. Flaud, R.R. Gamache, A. Goldman, D. Jacquemart, I. Kleiner, N. Lacome, W.J. Lafferty, J.Y. Mandin, S.T. Massie, S. Mikhailenko, C.E. Miller, N. Moazzen-Ahmadi, O.V. Naumenko, A. Nikitin, J. Orphal, A. Predoi-Cross, V. Perevalov, A. Perrin, C.P. Rinsland, M. Rotger, M. Šimečková, M.A.H. Smith, K. Sung, S. Tashkun, J. Tennyson, R.A. Toth, A.C. Vandaele, J. Vander Auwera, J. Quant. Spectrosc. Radiat. Transfer 110, 533 (2009)

14. N. Jacquinet-Husson, N.A. Scott, A. Chédin, L. Crépeau, R. Armante, V. Capelle, J. Orphal, A. Coustenis, C. Boonne, N. PouletCrovisier, A. Barbe, M. Birk, L.R. Brown, C. Camy-Peyret, C. Claveau, K. Chance, N. Christidis, C. Clerbaux, P.F. Coheur, V. Dana, L. Daumont, M.R. De Backer-Barilly, G. Di Lonardo, J.M. Flaud, A. Goldman, A. Hamdouni, M. Hess, M.D. Hurley, D. Jacquemart, I. Kleiner, P. Köpke, J.Y. Mandin, S. Massie, S. Mikhailenko, V. Nemtchinov, A. Nikitin, D. Newnham, A. Perrin, V.I. Perevalov, S. Pinnock, L. Régalia-Jarlot, C.P. Rinsland, A. Rublev, F. Schreier, L. Schult, K.M. Smith, S.A. Tashkun, J.L. Teffo, R.A. Toth, Vl.G. Tyuterev, J. Vander Auwera, P. Varanasi, G. Wagner, J. Quant. Spectrosc. Radiat. Transfer 109, 1043 (2008)

15. C. Frankenberg, J.F. Meirink, M. van Weele, U. Platt, T. Wagner, Science 308, 1010 (2005)
16. C. Frankenberg, P. Bergamaschi, A. Butz, S. Houweling, J.F. Meirink, J. Notholt, A.K. Petersen, H. Schrijver, T. Warneke, I. Aben, Geophys. Res. Lett. 35, L15811 (2008)

17. A. Perrin, D. Jacquemart, F. Kwabia Tchana, N. Lacome, J. Quant. Spectrosc. Radiat. Transfer 110, 700 (2009)

18. G. Casa, R. Wehr, A. Castrillo, E. Fasci, L. Gianfrani, J. Chem. Phys. 130, 184306 (2009)

19. P.M. Chu, F.R. Guenther, G.C. Rhoderick, W.J. Lafferty, J. Res. Natl. Inst. Stand. Technol. 104, 59 (1999)

20. S.W. Sharpe, T.J. Johnson, R.L. Sams, P.M. Chu, G.C. Rhoderick, P.A. Johnson, Appl. Spectrosc. 58, 1452 (2004)

21. G. Berden, R. Peeters, G. Meijer, Int. Rev. Phys. Chem. 19, 565 (2000)

22. A.K.Y. Ngai, S.T. Persijn, G. von Basum, F.J.M. Harren, Appl. Phys. B 85, 173 (2006)

23. E. Theocharous, J. Ishii, N.P. Fox, Appl. Opt. 43, 4182 (2004)

24. http://mark4sun.jpl.nasa.gov/report/c2h6_spectroscopy.pdf

25. P.G.J. Irwin, L.A. Sromovsky, E.K. Strong, K. Sihra, N.A. Teanby, N. Bowles, S.B. Calcutt, J.J. Remedios, Icarus 181, 309 (2006)

26. M.E. Klein, D.-H. Lee, J.-P. Meyn, K.-J. Boller, R. Wallenstein, Opt. Lett. 24, 1142 (1999)

27. G. von Basum, D. Halmer, P. Hering, M. Mürtz, S. Schiller, F. Müller, A. Popp, F. Kühnemann, Opt. Lett. 29, 798 (2004) 